\title{
Hydroxychloroquine in a G6PD-Deficient Patient with COVID-19 Complicated by Haemolytic Anaemia: Culprit or Innocent Bystander?
}

\author{
François Mastroianni ${ }^{1}$, Vincent Colombie ${ }^{1},{\text { Geraldine } \text { Claes }^{2} \text {, Axelle Gilles }}^{2}$, Frédéric Vandergheynst ${ }^{3}$, Sammy Place ${ }^{1}$ \\ ${ }^{1}$ Department of Internal Medicine, EpiCURA Hospital, Hornu, Belgium \\ ${ }^{2}$ Department of Haematology, EpiCURA Hospital, Hornu, Belgium \\ ${ }^{3}$ Department of Internal Medicine, Erasme Hospital, Brussels, Belgium
}

\section{Doi: 10.12890/2020_001875 - European Journal of Case Reports in Internal Medicine - @ EFIM 2020}

Received: 07/06/2020

Accepted: $13 / 07 / 2020$

Published: $18 / 08 / 2020$

How to cite this article: Mastroianni F, Colombie V, Claes G, Gilles A, Vandergheynst F, Place S. Hydroxychloroquine in a G6PD-deficient patient with COVID-19 complicated by haemolytic anaemia: culprit or innocent bystander? EJCRIM 2020;7: doi:10.12890/2020_001875.

Conflicts of Interests: The Authors declare that there are no competing interests.

This article is licensed under a Commons Attribution Non-Commercial 4.0 License

\section{ABSTRACT}

Hydroxychloroquine has been used worldwide as a first-line treatment for patients hospitalized with COVID-19. Little is known about COVID-19 and its effects on patients with congenital red blood cell disorders. We report a case of haemolytic anaemia in a 32-year-old patient and a fortuitous highlighting of G6PD deficiency. We reviewed the literature to assess the risk of hydroxychloroquine use in this context.

\section{LEARNING POINTS}

- A rapid drop in haemoglobin in COVID-19 patients should alert physicians to test for haemolytic anaemia and enzymopathies.

- Our review of the literature shows that use of hydroxychloroquine is safe in G6PD-deficient patients.

\section{KEYWORDS}

Haemolytic anaemia, G6PD deficiency, COVID-19, SARS-CoV-2

\section{INTRODUCTION}

The novel coronavirus disease 2019 (COVID-19) pandemic caused by severe acute respiratory syndrome coronavirus 2 (SARS-CoV-2) began in Wuhan, China, in December 2019, and has since spread worldwide. Haematological manifestations of COVID-19 include anaemia due to inflammatory syndrome, and a wide variation in white blood cell count ranging leucocytosis to leukopenia with lymphopenia appearing to be the most common manifestation ${ }^{[1]}$.

Hydroxychloroquine is an old drug usually indicated for rheumatic disease. It was introduced as a first-line treatment in Belgium for COVID-19 patients requiring hospitalization. This recommendation was based on data suggesting in vitro efficacy against SARS-CoV-2 ${ }^{[2]}$ and from a small study pre-published by Gautret et al. ${ }^{[3]}$.

\section{CASE DESCRIPTION}

A 32-year-old man of sub-Saharan African origin was hospitalized with suspected COVID-19. The patient was born in Belgium and reported no relevant medical history. He was obese with a body mass index of $37.6 \mathrm{~kg} / \mathrm{m}^{2}$. Nasopharyngeal swab PCR testing was positive for SARSCoV-2 and a CAT scan performed in the emergency department showed severe bilateral interstitial pneumonia involving more than $75 \%$ of the pulmonary parenchyma (Fig. 1). 
The patient's need for oxygen increased 24 hours after admission and he was admitted to the intensive care unit for observation. His respiratory parameters rapidly improved without intubation and he was transferred back to the ward. As recommended by national guidelines, the patient received a 5-day regimen of hydroxychloroquine (400 mg twice a day on day 1 then $200 \mathrm{mg}$ twice a day from day 2 to day 5).

A rapid the drop in haemoglobin level to $7.7 \mathrm{~g} / \mathrm{dl}$ on day 2 gave rise to concern (Fig. 2). The patient reported no blood loss. A complete blood test was performed and showed signs of haemolysis (the direct Coombs test was positive for polyvalent antiserum immunoglobulin unconjugated hyperbilirubinemia, high levels of lactate dehydrogenase, and consumption of haptoglobin). There were no schistocytes or reticulocytosis. There was no folate, vitamin B12 or iron deficiency. Screening for HIV and parvovirus B19 infection was negative.

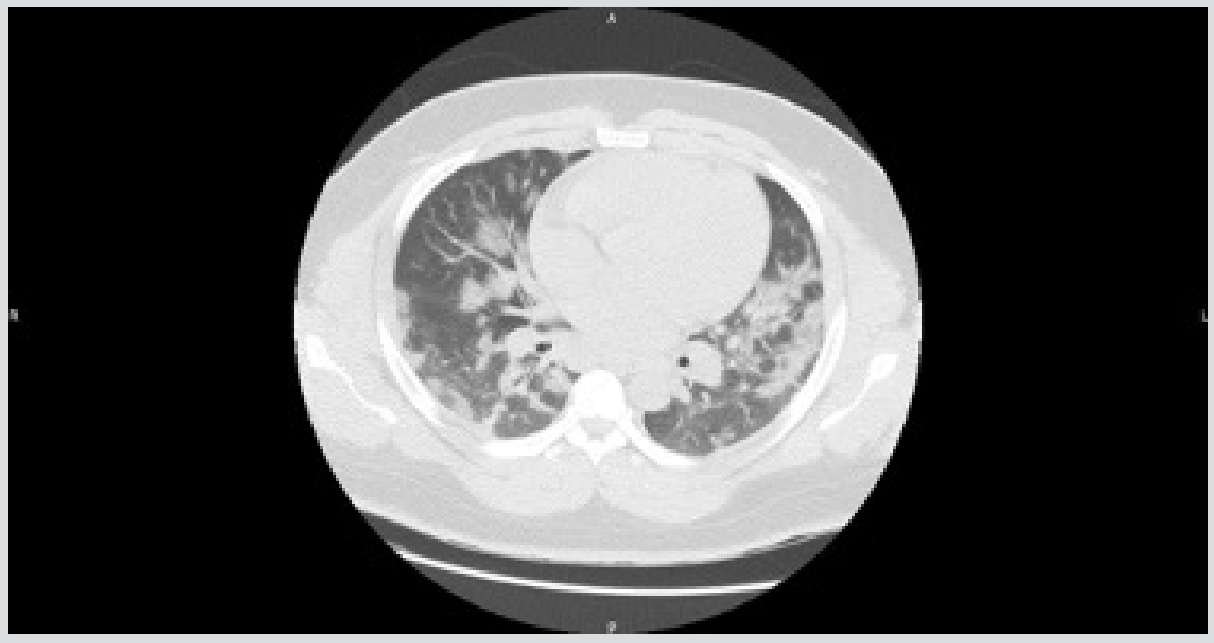

Figure 1. Admission CAT scan showing signs of severe bilateral interstitial pneumonia suggesting COVID-19 infection

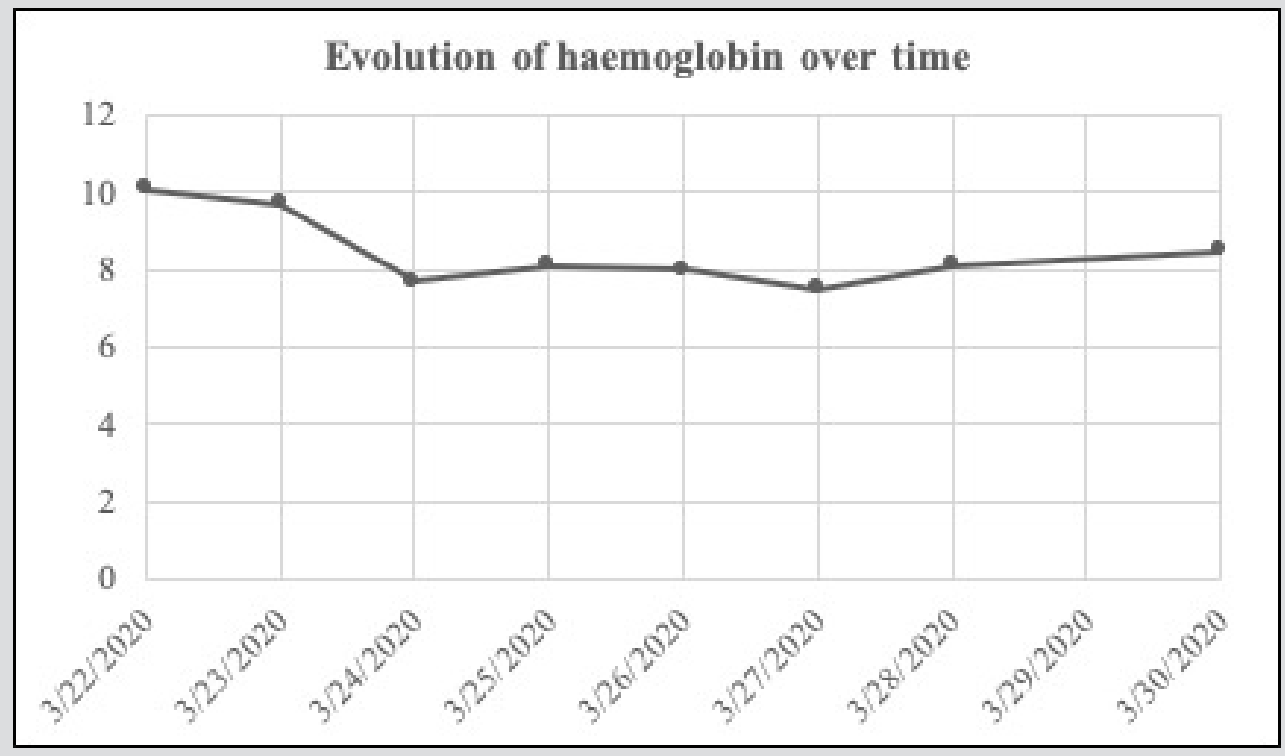

Figure 2. Evolution of haemoglobin over time

Screening for congenital red blood cell (RBC) disorders revealed a G6PD deficiency that was not known to the patient. The G6PD enzyme level was below $0.2 \mathrm{U} / \mathrm{g} \mathrm{Hb}$. The patient required a single transfusion of RBCs on day 2 after which his condition slowly improved. We stopped hydroxychloroquine administration and provided folic acid to support bone marrow regeneration. The patient's haemoglobin level on the day of discharge was stable at $8.7 \mathrm{~g} / \mathrm{dl}$.

\section{DISCUSSION}

Our patient showed biological signs of haemolytic anaemia and G6PD deficiency was identified. The lack of reticulocytosis was explained by the severe inflammatory syndrome resulting in absence of marrow regeneration. 
G6PD deficiency is the most common red cell enzyme deficiency and affects approximately 400 million people worldwide ${ }^{[4]}$. It has a global distribution but is more common in areas in which malaria is endemic, leading the hypothesis that G6PD deficiency provides a selective advantage against Plasmodium species. G6PD deficiency is an inherited X-linked disorder. As a result, males who inherit a G6PD mutation are hemizygous for the defect and all their RBCs are affected.

Various medications and chemicals as well as several foods and infections may elicit an episode of acute haemolysis in an individual with G6PD deficiency. G6PD is an essential intracellular enzyme that generates NADPH and protects RBCs from oxidative injury. A deficiency of this enzyme increases the vulnerability of erythrocytes to oxidative stress. G6PD-knockdown cells are more susceptible to viral infection ${ }^{[5]}$. Such susceptibility was shown in experimental research involving human coronavirus $229 \mathrm{E}{ }^{[6]}$. This study postulated that oxidative stress contributes to the enhanced susceptibility of these cells to coronavirus infections leading to a haemolysis crisis.

Caution is recommended when prescribing hydroxychloroquine in G6PD-deficient patients ${ }^{[7]}$. Hydroxychloroquine is a derivative of chloroquine, and also a 4-aminoquinoline. Many articles on drug safety in G6PD patients investigated chloroquine rather than hydroxychloroquine, but caution of use was then extended to hydroxychloroquine even though no exact association had been reported ${ }^{[7]}$ However, in 2010, Youngster et al. reviewed the literature to collect evidence on which to base decisions on whether to prohibit or allow the use of various medications in patients with G6PD deficiency. This review found no evidence against chloroquine monotherapy in G6PDdeficient patients ${ }^{[8]}$.

The risk of hydroxychloroquine administration was recently reviewed by two retrospective studies in 2018. Mohammad et al. analysed a cohort of 275 patients receiving hydroxychloroquine for rheumatic disease ${ }^{[9]}$. Only 11 of these patients had a G6PD deficiency and two had haemolysis when not taking hydroxychloroquine. There were no reported episodes of haemolysis during more than700 months of hydroxychloroquine exposure. Later, Saldarriaga et al. reported the same outcome with the same study design. Eighteen G6PD-deficient patients exposed to hydroxychloroquine showed no evidence of haemolysis ${ }^{[10]}$. These reviews provided no evidence that hydroxychloroquine is involved in the aetiology of haemolytic anaemia.

As previously mentioned, viral infections are known to cause oxidative stress in RBCs and haemolysis. A few cases of haemolytic anaemia in G6PD-deficient patients with COVID-19 are being reported ${ }^{[11-13]}$. As in other viral infections, we assume that haemolysis can be triggered by COVID-19. The role of hydroxychloroquine in this context remain obscure.

In light of these reviews of hydroxychloroquine use in G6PD-deficient patients, it is difficult to assess causality between hydroxychloroquine use and haemolysis in COVID-19 patients. A rapid drop in haemoglobin level should alert physicians to test for haemolysis. Further investigation is required to assess the relationship between COVID-19 and G6PD deficiency.

\section{REFERENCES}

1. Wang D, Hu B, Hu C, Zhu F, Liu X, Zhang J, et al. Clinical characteristics of 138 hospitalized patients with 2019 novel coronavirus-infected pneumonia in Wuhan, China. JAMA 2020;323(11):1061-1069.

2. Yao X, Ye F, Zhang M, Cui C, Huang B, Niu P, et al. In vitro antiviral activity and projection of optimized dosing design of hydroxychloroquine for the treatment of severe acute respiratory syndrome coronavirus 2 (SARS-CoV-2). Clin Infect Dis 2020 Mar 9. doi: 10.1093/cid/ciaa237 [Epub ahead of print].

3. Gautret P, Lagier J-C, Parola P, Hoang VT, Meddeb L, Mailhe M, et al. Hydroxychloroquine and azithromycin as a treatment of COVID-19: results of an open-label nonrandomized clinical trial. Int J Antimicrob Agents 2020 Mar 20. doi: 10.1016/j.ijantimicag.2020.105949 [Epub ahead of print].

4. Cappellini MD, Fiorelli G. Glucose-6-phosphate dehydrogenase deficiency. Lancet 2008;371(9606):64-74.

5. Ho HY, Cheng ML, Weng SF, Chang L, Yeh TT, Shih SR, et al. Glucose-6-phosphate dehydrogenase deficiency enhances enterovirus 71 infection. J Gen Virol 2008;89:20802089.

6. Wu YH, Tseng CP, Cheng ML, Ho HY, Shih SR, Chiu DTY. Glucose-6-phosphate dehydrogenase deficiency enhances human coronavirus $229 \mathrm{E}$ infection. J Infect Dis 2008;197(6):812-816.

7. G6PD Deficiency Association website - Official drug list: https://www.g6pd.org/en/G6PDDeficiency/SafeUnsafe.aspx

8. Youngster I, Arcavi L, Schechmaster R, Akayzen Y, Popliski H, Shimonov J, et al. Medications and G6PD deficiency: an evidence-based review. Drug Saf 2010;33(9):713-726.

9. Mohammad S, Clowse MEB, Eudy AM, Criscione-Schreiber LG. Examination of hydroxychloroquine use and hemolytic anemia in G6PDH-deficient patients. Arthritis Care Res (Hoboken) 2018;70(3):481-485.

10. Mejia Saldarriaga M, Ramirez de Oleo IE, Johnson B. Retrospective study: association of hydroxychloroquine use and hemolytic anemia in patients with low levels of glucose-6phosphate dehydrogenase (G6PD) [abstract]. Arthritis Rheumatol 2018;70(Suppl 10).

11. Beauverd Y, Adam Y, Assouline B, Samii K. COVID-19 infection and treatment with hydroxychloroquine cause severe haemolysis crisis in a patient with glucose-6-phosphate dehydrogenase deficiency. Eur J Haematol 2020 Apr 23. doi: 10.1111/ejh.13432 [Epub ahead of print].

12. Maillart E, Leemans S, Van Noten H, Vandergraesen T, Mahadeb B, Salaouatchi MT, et al. A case report of serious haemolysis in a glucose-6-phosphate dehydrogenase-deficient COVID-19 patient receiving hydroxychloroquine. Infect Dis (Lond) 2020 Jun 4. doi: 10.1080/23744235.2020.1774644 [Epub ahead of print].

13. Afra TP, Nampoothiri RV, Razmi TM. Doubtful precipitation of hemolysis by hydroxychloroquine in glucose-6-phosphate dehydrogenase deficient patient with COVID-19 infection. Eur J Haematol 2020 Jun 5. doi: 10.1111/ejh.13460 [Epub ahead of print]. 